\title{
A tricky case of pancreatic arteriovenous malformation: the role of endoscopic ultrasound in the diagnosis of this rare condition
}

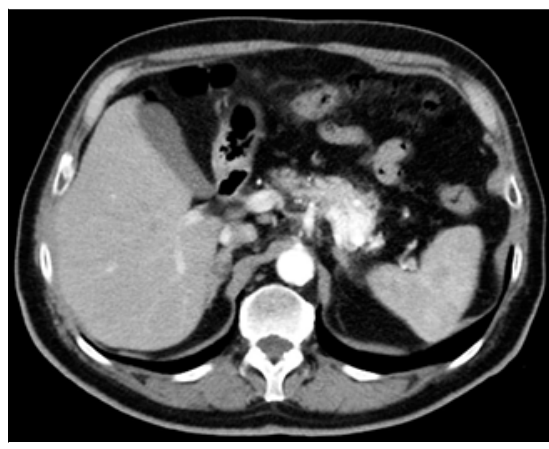

- Fig. 1 Nodular neoformation in the pancreatic tail, which was hyperintense in the arterial phase.

A 77-year-old man was referred to our hospital for further evaluation of a symptomatic pancreatic mass.

Almost a year before, he had experienced low back pain with irradiation to the left flank. Ultrasonography showed a hypoechoic mass at the pancreatic tail. He had no relevant past history, such as abdominal trauma, pancreatitis or other congenital abnormalities. His physical examination and laboratory test results were normal. Computed tomography (CT) revealed the presence of a nodular neoformation in the pancreatic tail, which was hyperintense in the arterial phase ( $\triangleright$ Fig. 1). A neuroendocrine tumor was suspected and endoscopic ultrasound (EUS) was performed.

A 25-mm vascular lesion in the pancreatic tail was detected, close to the splenic artery, from which it appeared to receive vascularization, with arterial flow seen on the color and power Doppler study ( $\triangleright$ Fig. 2, $\triangleright$ Video 1 ). On infusion of contrast agent (SonoVue $4.8 \mathrm{~mL}$; Bracco Imaging, Milan, Italy) rapid capture and slow release was shown ( $>$ Fig. 2 , - Video 1). Selective angiography of the celiac tripod confirmed the presence of an arteriovenous malformation (AVM) in the pancreatic tail, supplied by pancreatic branches of the splenic artery ( $\triangleright$ Fig. 3,

- Video 1). Given the symptomatology and the size of the lesion, left pancreatectomy and splenectomy was performed. Histological examination on the surgical sample confirmed the vascular origin of the lesion.

Pancreatic AVM is a very rare condition. It may be congenital or acquired in a neoplastic, traumatic or inflammatory context [1]. Most cases of pancreatic AVMs are symptomatic, most frequently presenting with abdominal pain and upper gastrointestinal bleeding, and only rarely with acute pancreatitis [2]. Diagnosis is usually made by ultrasonog-
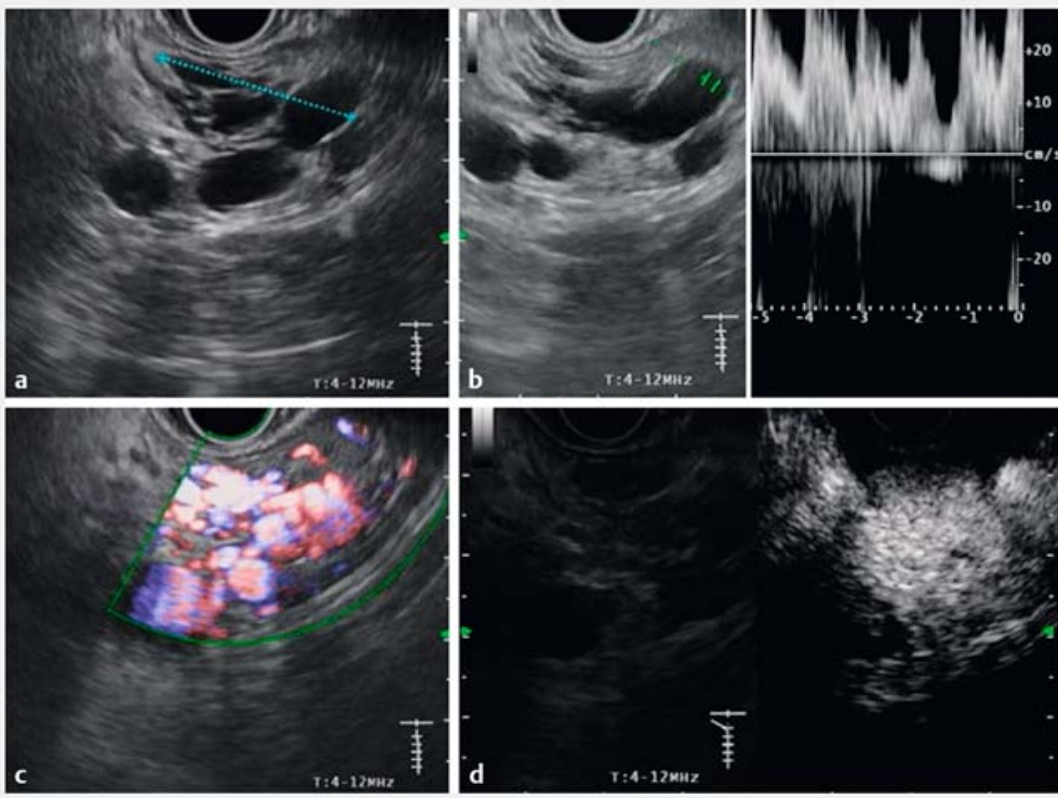

- Fig. 2 Endoscopic ultrasound images. a A $25-\mathrm{mm}$ vascular lesion was seen in the pancreatic tail, close to the splenic artery, from which it appeared to receive vascularization. $\mathbf{b}$ Arterial flow at power Doppler study. $\mathbf{c}$ Vascular pattern at color Doppler study. $\mathbf{d}$ Rapid capture and slow release following infusion of contrast agent (SonoVue $4.8 \mathrm{~mL}$; Bracco Imaging, Milan, Italy).

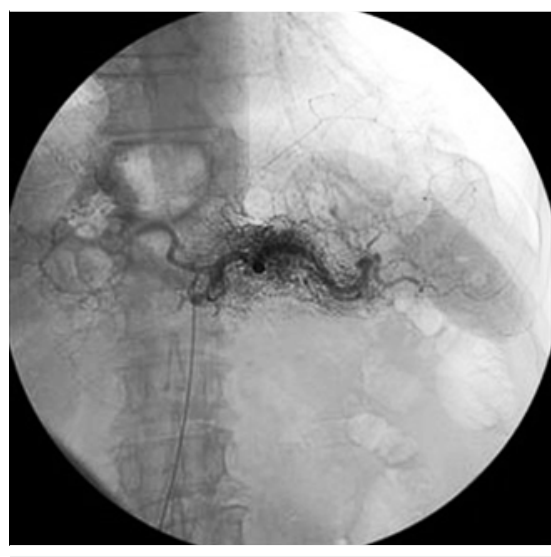

- Fig. 3 Arteriovenous malformation of the pancreatic body supplied by multiple pancreatic branches of the splenic artery. 


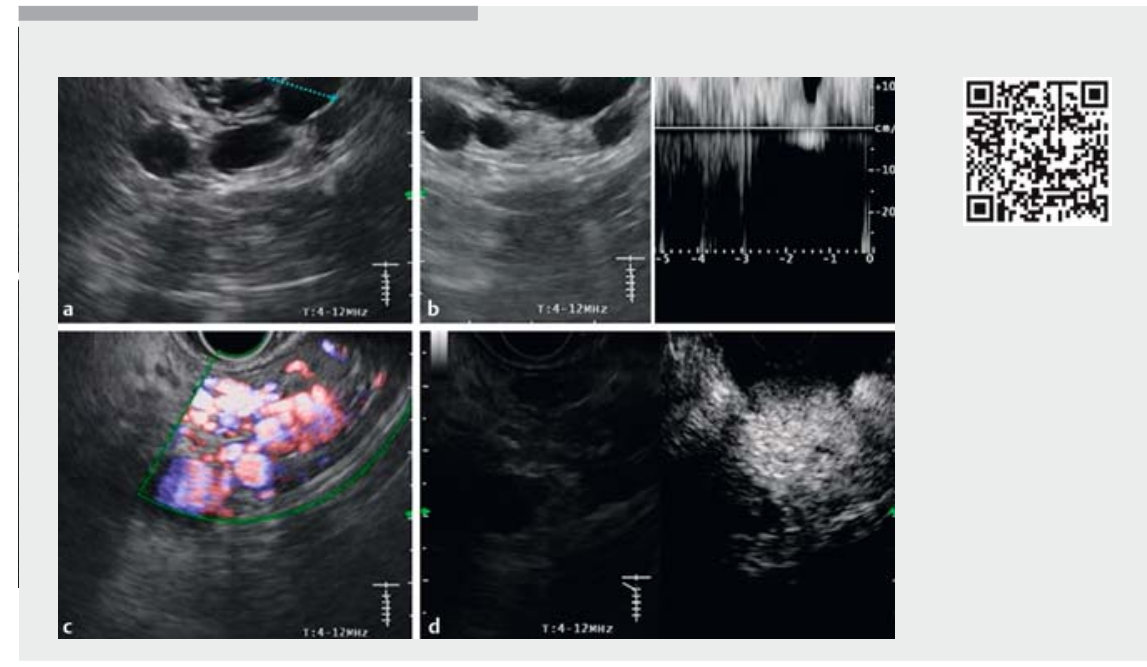

$\checkmark$ Video 1 Endoscopic ultrasound examination with Doppler study and contrast-enhanced evaluation followed by angiographic study confirmed the presence of a pancreatic arteriovenous malformation.

raphy, $\mathrm{CT}$, magnetic resonance imaging, and/or angiography [3]. The differential diagnosis is primarily hypervascular tumors such as islet cell tumor, neuroendocrine tumor, and hypervascular metastases [2]. In our case, EUS, which is not commonly performed in this condition, allowed the diagnosis to be made.

Endoscopy_UCTN_Code_CCL_1AF_2AZ_3AD

\section{Competing interests}

None
The authors

Ilenia Barbuscio', Alberto Fantin², Matteo Ghisa ${ }^{1}$, Lucia Moletta ${ }^{1}$, Cosimo Sperti ${ }^{1}$, Fabio Farinati ${ }^{1}$

1 Department of Surgical, Oncological and Gastroenterological Sciences,

Gastroenterological Section, University of Padua School of Medicine and Surgery, Padua, Italy

2 Department of Surgical, Oncological and Gastroenterological Sciences, Hospital of Padua, Padua, Italy

\section{Corresponding author}

Ilenia Barbuscio, MD

Department of Surgical, Oncological and Gastroenterological Sciences, Azienda Ospedaliera di Padova, Via Nicolò Giustiniani 2, Padova 35128, Italy Fax: +39-049-8212887 ilenia.barbuscio@gmail.com

\section{References}

[1] Lee M, Marusawa H, Yamashita Y. Gastrointestinal: recurrent pancreatitis due to pancreatic arteriovenous malformation. J Gastroenterol Hepatol 2015; 30: 2

[2] Chang S, Lim HK, Lee WJ et al. Arteriovenous malformation of the pancreas in a patient with gastrointestinal bleeding: helical CT findings. Abdom Imaging 2004; 29: 259 262

[3] Nikolaidou O, Xinou E, Papakotoulas P et al. Pancreatic arteriovenous malformation mimicking pancreatic neoplasm: a systematic multimodality diagnostic approach and treatment. Radiol Case Rep 2018; 13: 305 309

\section{Bibliography}

DOI https://doi.org/10.1055/a-0767-6283

Published online: 23.11.2018

Endoscopy 2019; 51: 195-196

(c) Georg Thieme Verlag KG

Stuttgart · New York

ISSN 0013-726X

\section{ENDOSCOPY E-VIDEOS \\ https://eref.thieme.de/e-videos}

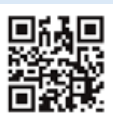

Endoscopy E-Videos is a free access online section, reporting on interesting cases and new techniques in gastroenterological endoscopy. All papers include a high quality video and all contributions are freely accessible online.

This section has its own submission website at https://mc.manuscriptcentral.com/e-videos 